\title{
UTILIZING THE EFFECT OF AIR SPEED TO IMPROVE AUTOMOBILE MOVING PERDORMANCE
}

\section{Dr. Masoud Fathizadeh, Purdue University Calumet (College of Technology)}

Masoud Fathizadeh - PhD, PE Professor Fathizadeh has been with the Department of Electrical and Computer Engineering Technology Purdue University Calumet since 2001. He has worked over 15 years both for private industries and national research laboratories such as NASA, Argonne and Fermi National Laboratories. Dr. Fathizadeh has established his own consulting and engineering company in 1995 specializing in power system, energy management and automation systems. During last twenty years the company performed many private and government projects. Dr. Fathizadeh has published numerous journal, conference and technical articles. He has been instrumental figure in establishing mechatronic engineering technology at Purdue University Calumet. His areas of interests are, control systems, power systems, power electronics, energy, and system integration. Dr. Fathizadeh is a registered professional engineer in the State of Illinois.

\section{Mr. Kevin E Horecky}

I was born and raised in St. John, IN. Growing up in regards to boredom or video games my father always said, "Our garage has every tool known to man." This really set me on the right path at an early age. I was always tinkering with something or other, striving to learn how and why things work the way they do. In the third grade my grandparents bought me a sailboat; this is when I fell in love with the effects of aerodynamics. I am now on my 5th sailboat, a 30 footer I sail on Lake Michigan. At Lake Central High School I ran Cross Country and Track. It was terrific fun being a part of a team working towards a common goal. The Competition was also enthralling. After the Chicago Marathon in 2010 I would give up running, but I still desired some good organized competition. So the following year I bought a Mazda Miata and quickly went to work modifying it for the sole purpose of going fast around a race track. I race Autocross mostly with the Sports Car Club of America, last year I got 15th in my class at Nationals. I also began racing Sailboats. Regattas are great team sports of tactical decision making and piloting that can be as crucial as piloting a racecar. After High school I went on to study Electrical and Computer Engineering Technology at Purdue University Calumet. While there, I started working as an intern at United States Steel, and I went on to take a position full time after graduation. 


\title{
UTILIZING THE EFFECT OF AIR SPEED TO IMPROVE AUTOMOBILE MOVING PERFORMANCE
}

\begin{abstract}
A senior design project to practically implement the effect of wind speed on a race car is conducted. This project exposed student with actual system rather than some simulation kits. The student experienced the difference between the theoretical and actual result and learned how to design a signal conditioning circuit to convert the measured values into a realistic and meaningful data. The effect of air pressure on moving cars was investigated to find the relationship between air speed and lift forces. The measured values are utilized to adjust spoilers and wings attack angles. The race cars, by the use of spoilers and wings, capture the airflow, manipulate it and turn it into down force to increase traction at higher speeds. This seems counterintuitive since race cars need to be light. However, it is the mass that is important and is limiting. The mass doesn't change, regardless of the gravity and the atmosphere. Weight, on the other hand, as it relates to cars is always changing with bumps on the road, speed and direction. Measuring these effects on cars has been achieved through the use of wind tunnels in the past. The attack angles for the wings and spoilers play a major role in suppressing the lifting problem. This paper investigates the lifting problem for a sport car on a race track and measures the lifting forces exerted on each corner of the car. The data collected from each sensor is used to adjust the spoiler attack angle at different speeds under variety of turning conditions. The proposed system has been installed on a sport car and its performance has been monitored and the relevant data has been collected. The adjustment of the spoiler led to improved performance of the car.

This paper describes:

1. The theory of airflow and its lift effect on moving cars

2. Measurement mechanism, electronic sensors, data manipulation, data management, and spoiler adjustment

3. Track testing and analysis of results

4. Senior design project as an experiential learning tool
\end{abstract}

\section{INTRODUCTION}

As a car travels forward, it is attacked by moving air particles. These air particles go over, under and around the sides of a car. The air particles on top of a car experience lower pressure and consequently with less air density while the air particles under the car are compressed and result in higher air density. The lower air pressure on the top and the higher pressure under the car cause the car to lift. The lifting forces are not distributed uniformly for every corner of a car, especially when a car makes a turn [1-3]. These uneven lifting forces limit the capability of a car to make turns at higher speed. This phenomenon is more pronounced in racing cars than average passenger cars. For example a 2700 pounds car can produce $742 \mathrm{lbs}$ of lift at $124 \mathrm{mph}$ which is nearly $1 / 4$ of its weight at that speed [4-5]. This lifting force reduces a car's capability of gripping the road and may cause stability problems [6-7]. In this project, it is intended to measure the aerodynamic effect on a car with respect to speed changes, as it relates to weight. Several small film pressure transducers are installed between the coilover spring and spring perch of a Mazda 
Miata sports car. At rest, the pressure transducers show the weight of the car: minus the wheels, tires, control arms, brakes, shock, springs, and steering knuckles. This group of parts in the automotive world is known as unsprung weight. Transducer signals are conditioned to isolate the effect of bumps on the road, and are combined separately into two groups, one for the front and another for the rear. This set-up provides two sets of readings, for the front and the rear weight. Graphs are plotted for weight versus speed changes indicating the increase of weight caused by down force or decrease of weight due to the lift force (Figure 9). The car is modified with the installation of diffusers, splitters, wings, and canards to measure lift, or down force at different speeds. Finally the car is driven on a race track; a road course featuring both left and right turns. At the race track, the car is driven a series of laps with and without aerodynamic pieces and comparisons were made between: lap times, minimum cornering speed, and maximum straight away speed. The graph of the down force vs. speed shows any gain or loss in the car performance. The purpose of this experiment is to duplicate some of the measurements that large engineering firms or automotive companies can produce in wind tunnels. There is little research or evidence of anyone trying to make these measurements on the fly in the past. The purpose of this individual measurement is to help a race team tune their car to produce the right amount of down force regardless of equal distribution of weight on front and rear, or a type of race.

\section{THEORY OF OPERATION}

The lift force can be calculated using the Bernoulli's or its derivation Euler's equations. In the calculation the effect of viscosity is assumed to be negligible, the air to be incompressible and frictionless.

Furthermore, there can be no energy sources or sinks along the streamline. The Bernoulli's equation is applied along a streamline, taking the form [6-7]:

$$
\left(P_{1} / p\right)+(1 / 2) v_{1}^{2}+g z_{1}=\left(P_{2} / p\right)+(1 / 2) v_{2}^{2}+g z_{2}=a \text { constant }
$$

Where:

$\mathrm{P}$ : the pressure of the fluid ( $\mathrm{Pa}, \mathrm{PSI})$

$\rho$ : the density of fluid $\left(\mathrm{Kg} / \mathrm{m}^{3}, \mathrm{lbm} / \mathrm{ft}^{3}\right)$

$v$ : the velocity of the fluid relative to the airfoil $(\mathrm{m} / \mathrm{s}, \mathrm{ft} / \mathrm{s})$

$g$ : the magnitude of acceleration for body $\left(\mathrm{m} / \mathrm{s}^{2}, \mathrm{ft} / \mathrm{s}^{2}\right)$

$z$ : the height at that point $(\mathrm{m}, \mathrm{ft})$

The subscripts 1 and 2 represent different points along the same streamline of fluid flow.

When a car turns, a force must accelerate the car towards the center of the turn.

\section{AERODYNAMIC OVERVIEW}

There are many different aerodynamic effects taking place on a car at different locations. For some locations the car is producing lift while others the car is experiencing down-force. Figure 1, shows a Mazda Miata (the test car) and all the different forces taking place due to air speed. 


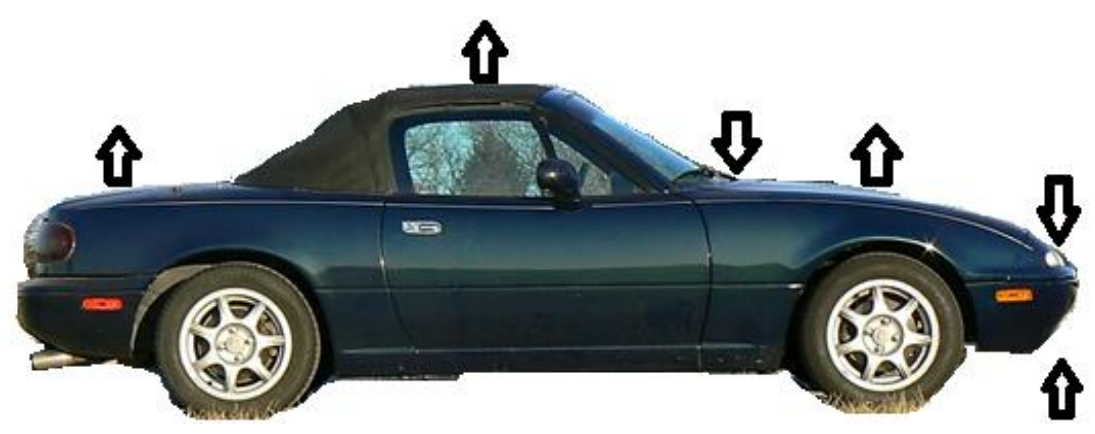

Figure-1 Test car with all different forces due to air speed

The arrows represent areas of high pressure pushing towards areas of low pressure. For example the arrow on the roof pointing up is due to the pressure under the car is higher than the pressure on the roof. The arrow pushing down on the windshield wipers is a high pressure area on top pushes the car towards the relative low pressure area under the car. The reason for modifying a car shape is to produce more downforce to increase the high-pressure on the top of the car and to increase the low pressure under the car. Race and sports cars add both front air dam as well as a splitter to achieve such a goal. An air dam (a vertical section from the further point forward on a car extending down to the road) forces most of the air hitting the car to flow over the hood as opposed to under the car. This helps creating a low pressure zone under the whole car. The splitter (A horizontal board extending forward from the bottom of the bumper or air dam) is the divider between high pressure and low pressure. The high pressure on top of the splitter pushes the splitter towards the low pressure below it. A wing which is no more than an inverted airplane wing can be installed to improve the car stability. Its shape produces high pressure on top and low pressure on bottom, which results in down force. A spoiler on the other hand, like those used in NASCAR, produces the same effects of a wing except it slows the flow of air over the trunk making a high pressure zone that pushes down towards the lower pressure under the car. Another aerodynamic element is the rear diffuser. The diffuser creates additional low pressure under the rear of the car while it helps makes a smoother transition of air flow from the body of the car to the near vacuum directly behind the car. Finally the last element added to the car is simply adding smooth underbody panels under the car to keep the air flowing fast and generating low pressure [8-9].

\section{SYSTEM DESCRIPTION}

The design includes 24 force sensors, 6 at each corner of the car. The front and rear 12 sensors are combined to give the user 2 readings, front and rear weight. An analog circuit is developed to process the signals, dampen noise, and average their magnitudes. The two voltage signals are recorded and graphed vs. speed.

\section{SENSOR PLACEMENT}

The sensors are placed where the sprung mass and unsprung mass meet on the car. This location is at the bottom of the Coil-over (shock and spring assembly). This configuration is shown in Figures 2 and 3. 


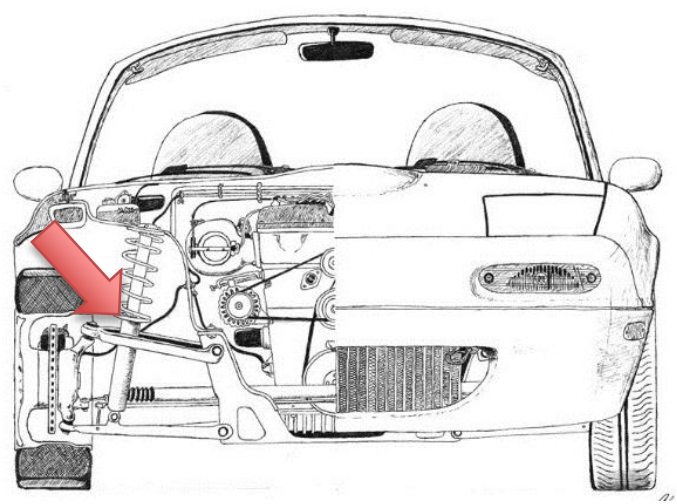

Figure-2 A cut-away view of a Miata with an arrow pointing the location of the sensor placement. (Forum.miata.net)

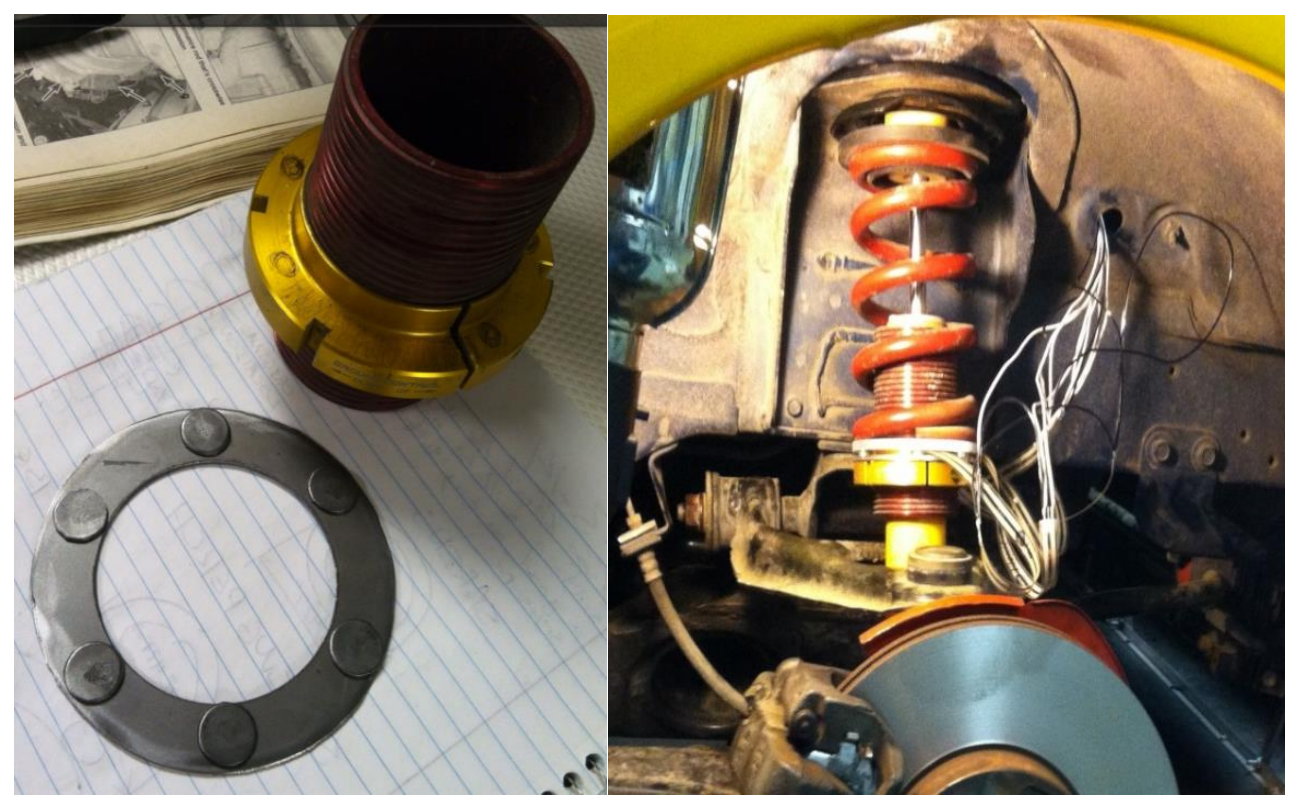

Figure-3 Top-hat where the sensor are mounted

This prelimenary design, made from sheet metal, didn't offer a flat enough mating surface. The individual output voltages between sensors were very far apart indicating uneven and non-flat rings. A set of specially made rings were machined from aluminum to meet this stringent requirement. These rings were almost perfectly flat. The rings serve as the mounting platform to insure that all the weight is transferred from the spring to the spring perch through the sensors. In Figure 4 on the left hand, the arrow points to the sensor mounting location where on the right the machined aluminum mating surfaces is shown. 


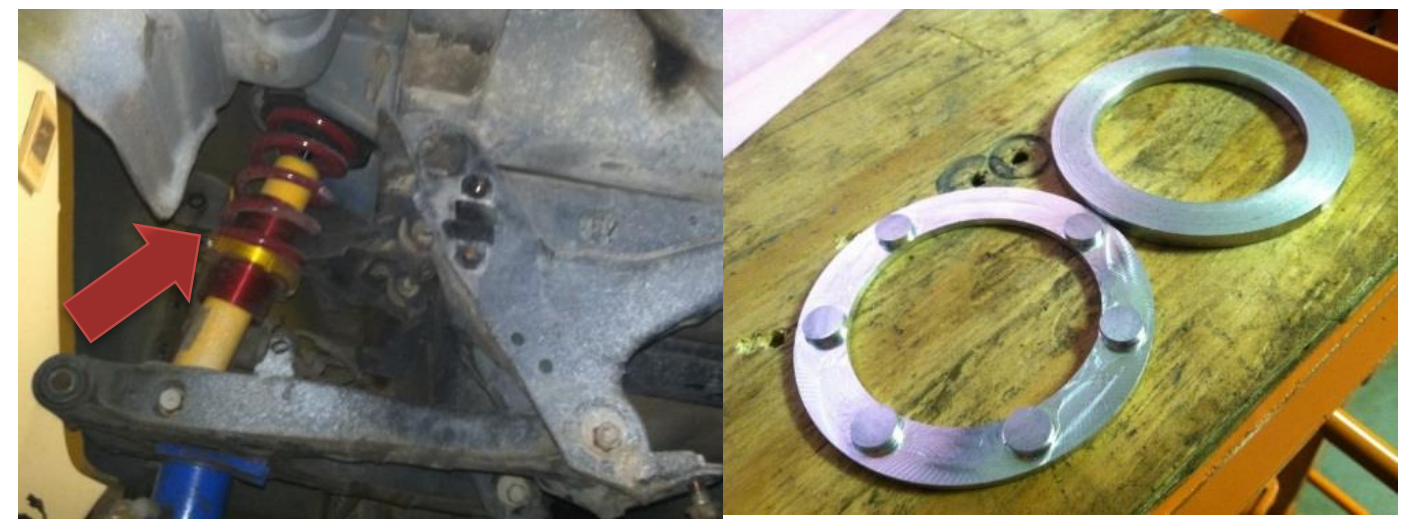

Fiigure-4 An arrow on the left highlights the sensor location. On the right, top hat bolted where the sensor are making contact

\section{TRANSDUCER SENSORS}

The sensor used for this project is a Tekscan FlexiForce sensor. Tekscan provides the following definition of their product:

1. A versatile, durable Piezo resistive force sensor that can be made in a variety of shapes and sizes; a Piezo resistive sensing device in which resistance is inversely proportional to applied force;

2. A customizable force sensor and economical force measurement tool that is easily integrated into OEM products;

3. A patented, ultra-thin (0.008 in.), flexible printed circuit that senses contact force; a force and load sensor that is available in varying force ranges and standard models (A201, A301, A401, HT201), suiting a variety of applications for research and product development/testing

The Tekscan sensor is the A201 force sensor. The sensor offers a sensing range up to one hundred pounds with $+/-3 \%$ error. It has a small sensing area of 0.375 inch diameter. This is perfect for this application. Tekscan does offer a high heat version of the product which I should be using since the A201 is only rated up to 140 degrees Fahrenheit. However, since the testing will only be done in a non-race environment the under hood temperatures should stay cool enough. Figure 5 shows the sensor.

$\begin{array}{ll}\text { SENSOR SPECIFICATIONS } & \\ \text { Thickness: } & 0.203 \mathrm{~mm}(0.008 \mathrm{in} .) \\ \text { Length: } & 191 \mathrm{~mm}(7.5 \mathrm{in} .)^{*} \\ \text { Width: } & 14 \mathrm{~mm}(0.55 \mathrm{in} .) \\ \text { Sensing Area: } & 9.53 \mathrm{~mm}(0.375 \mathrm{in} .) \text { diameter } \\ \text { Connector: } & \text { 3-pin Male (center pin is inactive) } \\ \text { Substrate: } & \text { Polyester (ex: Mylar) } \\ \text { Pin Spacing: } & \text { 2.54 mm }(0.1 \text { in. }) \\ \text { Linearity (Error): }< \pm 3 \% & \\ \text { Repeatability: } & < \pm 2.5 \% \text { of full scale } \\ \text { Hysteresis: } & <4.5 \% \text { of full scale }\end{array}$




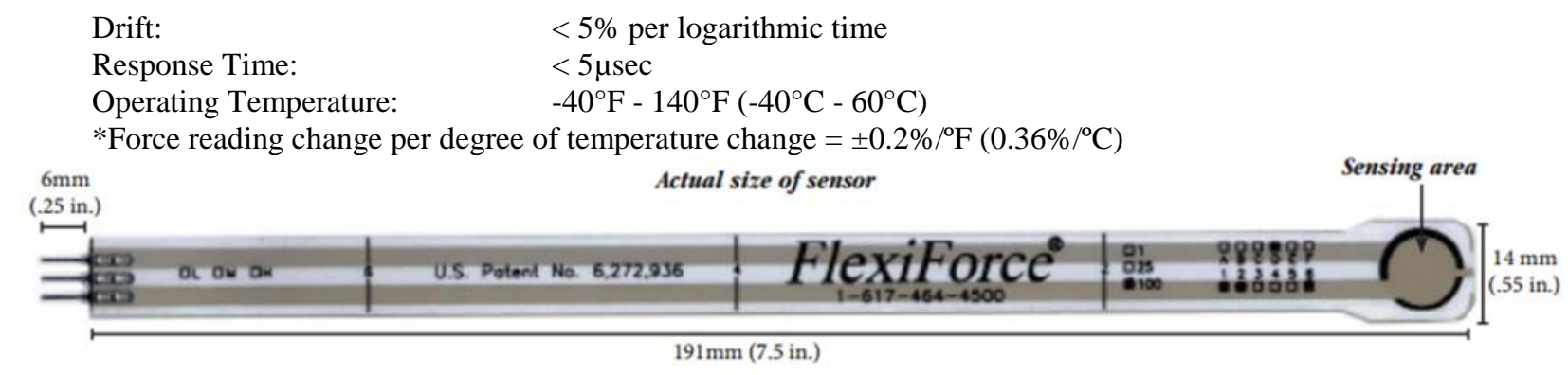

Figure-5 Flexiforce A201 Force sensor (Tekscan.com)

The Piezo resistive force sensor works indicating changing resistance with force. When the sensor is unloaded the resistance reads very high, about $10 \mathrm{M} \Omega$, and the resistance decreases with increased applied force. Figure 6 is the manufacturer's graph representing conductance with respect to force. The black line represents perfect linearity while the purple line represents the actual correlation.

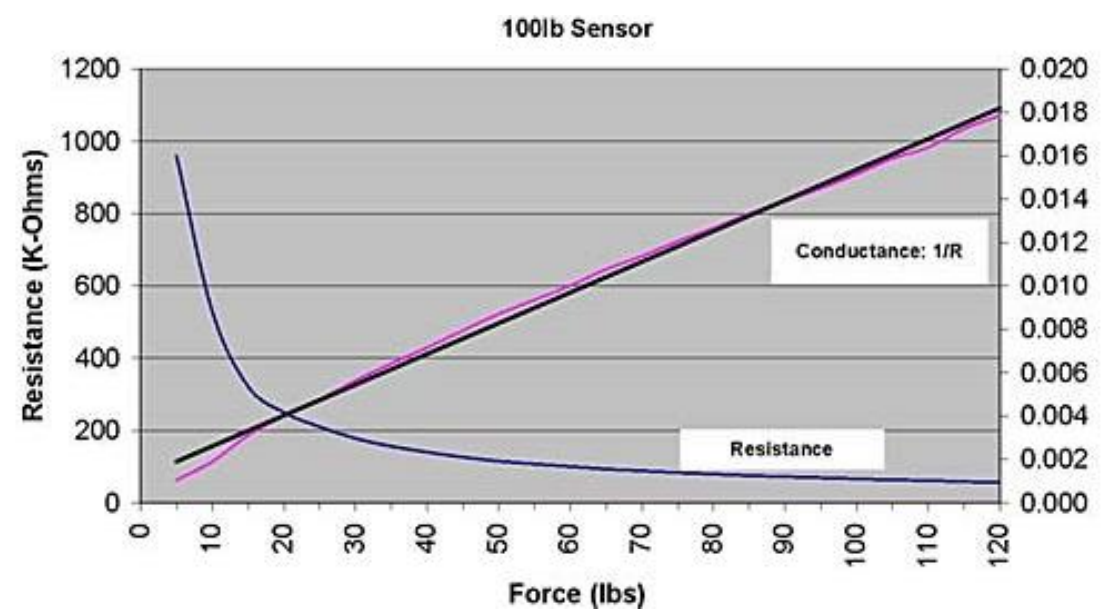

Figure-6 Sensor data provided by manufacturer with measured data superimposed

An electronic circuit is designed to convert the resistance variation into the voltage variation. This circuit is shown in Figure 7.

Preliminary testing of the $100 \mathrm{lbs}$ version of the A201 shows the output is fairly linear. Figure 8 shows the test results of 6 different sensors, with each sensor having 3 different tests. All the like colors on top of each other show that the sensors are repeatable. With three separate tests, the resistance values are the same. The lines plotted are also straight showing linearity of the output with respect to force. The difference from sensor to sensor though, is something that will have to be worked around. Sensor F has nearly half the resistance at $100 \mathrm{lbs}$ as sensor D has at the same weight. To overcome this difference, the electronic for each sensor is calibrated for its specified sensor using the adjustable $\mathrm{R}_{\mathrm{f}}$ potentiometer. 


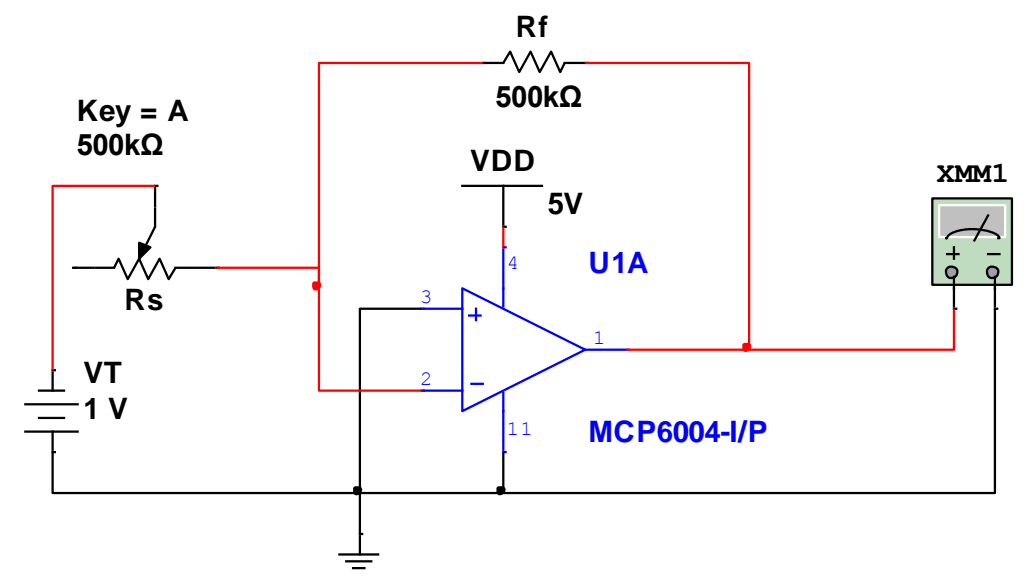

Figure-7 Electronic circuit used to convert changing resistance into voltage variation.

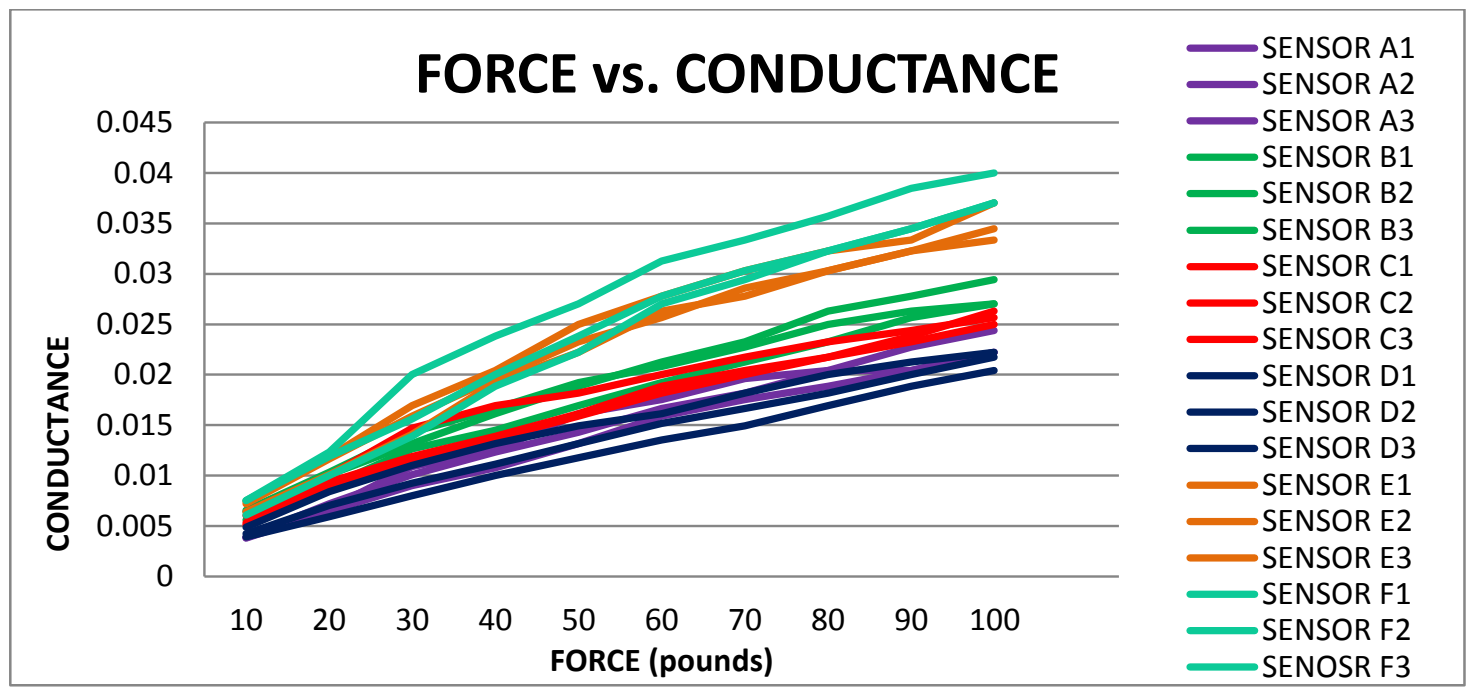

Figure-8 Plot for multiple sensors response with applied force $[\mathrm{lbs}]$ and conductance $[1 / \Omega]$

The output voltage against weight changes is plotted and shown in Figure 9. The measured values closely conforms to the straight line that represents the manufacturer's suggested performance curve. 


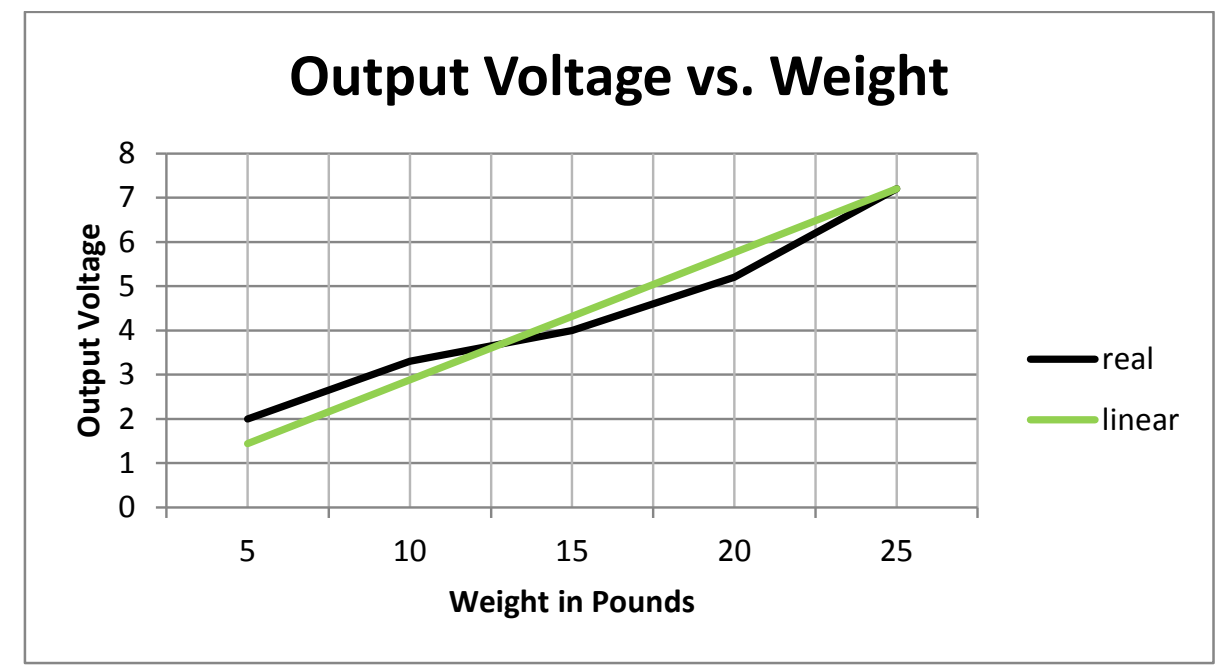

Figure-9 Linearity found after utilizing a basic operational amplifier circuit

\section{SINGAL PROCESSING}

Due to an always changing road conditions the voltage signals have large amounts of noise proportional to bumps on the road. The momentary shocks on individual corners could exceed thousands of pounds. In order to combat this real world occurrence, a low pass filter (LPF) has been added to dampen the noise. In Figure 10 , the $R_{3}$ and $R_{4}$ are being used as a voltage divider to represent the varying signal of the force sensors. $\mathrm{R}_{2}$ and $\mathrm{C}_{1}$ make up the low pass filter. The values are adjusted to tune the actual damping to the desired response when the system works on the car. Figure 10 representing the simulated response of the LPF. The Red trace represents the input voltage to the LPF while the green trace represents the damped signal.

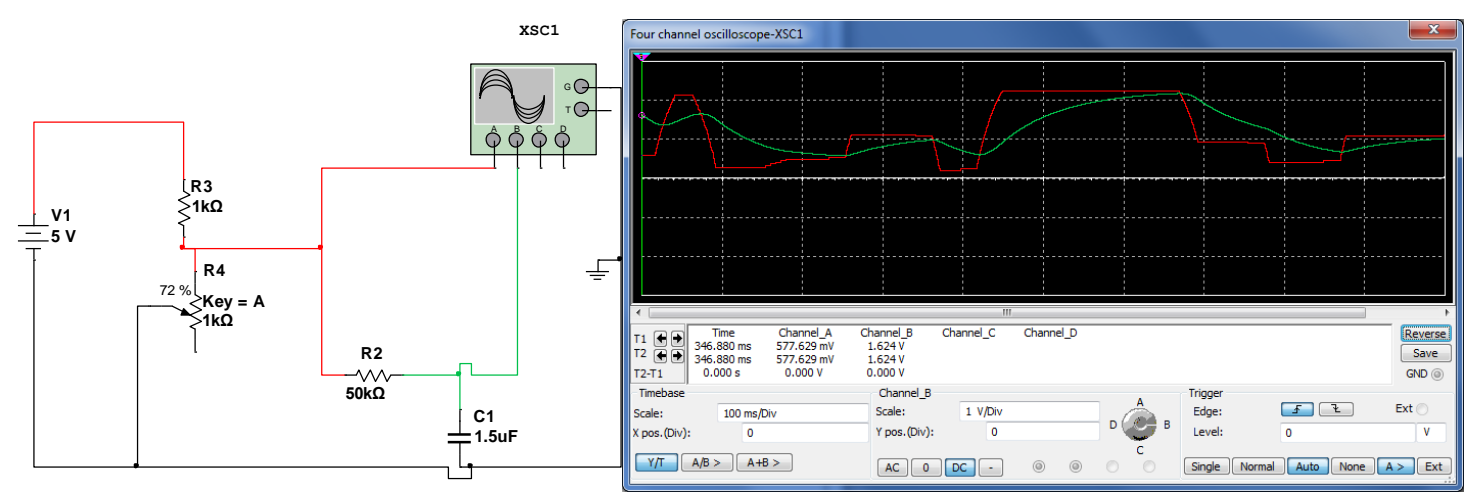

Figure-10 A typical Low Pass filter and its output response used to reduce the noise effect due to bumps on the road 
For the final outcome of this project, two signals are available, a front signal representing front weight and a rear signal, for rear weight. Yet there are six individual sensors on each corner. That means, twelve, 0-14 volt signals are to be damped and averaged to give one average number. The averaging circuit utilizes resistors in parallel and is shown in Figure 11. The Averaging circuit works only for equal resistor values with its output equal to the sum of voltages divided by the number of resistors.

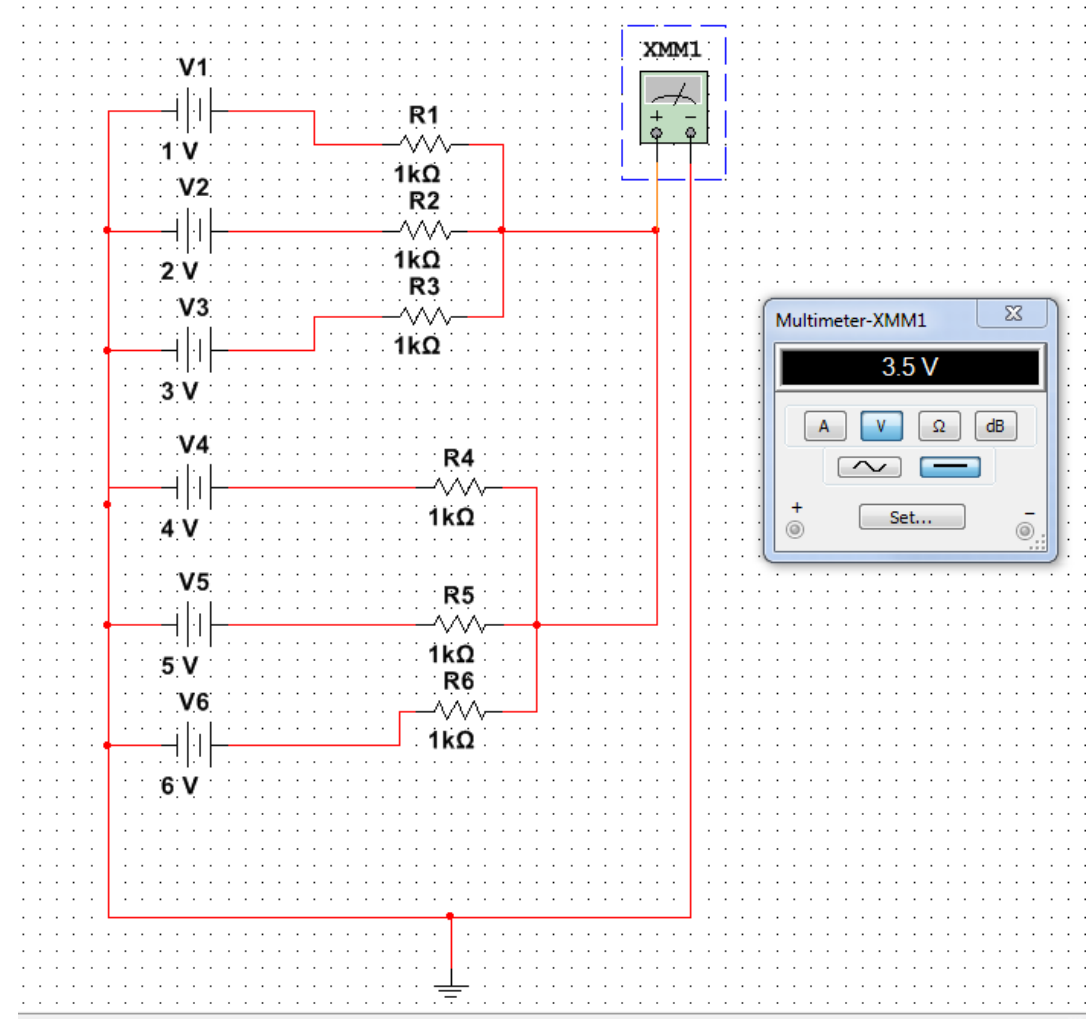

Figure-11 Averaging circuit used for producing the average values of the sensor outputs

The force sensors are represented by potentiometers and the values at this point are to be tuned. Figure 12 represents the total circuit diagram for one corner of the car. 

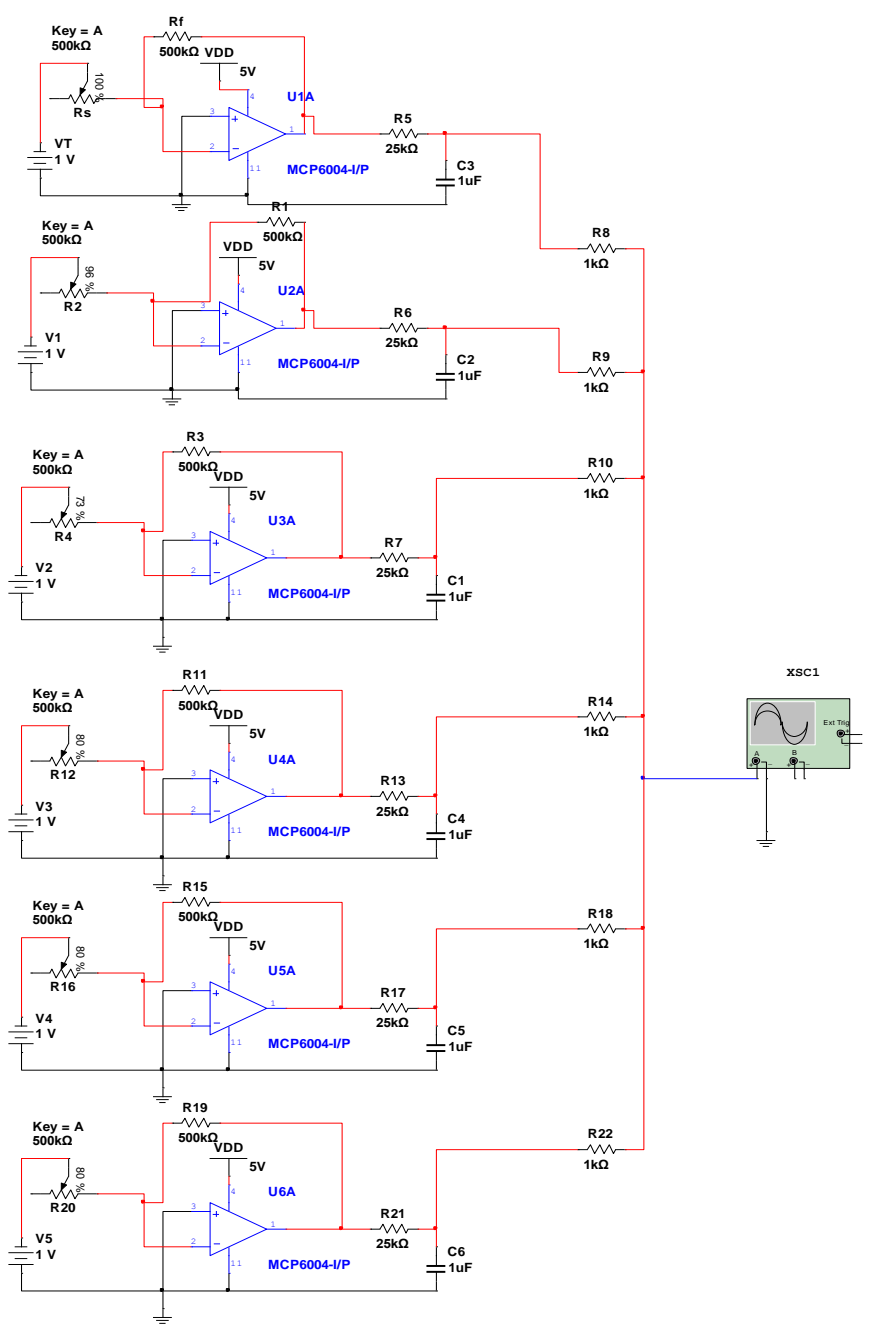

Figure-12 Complete circuit diagram for one corner of the car

\section{TESTING}

All circuit components are assembled on one common board and tested for each individual corner measurements. To make sure about the functionality of each sensor, a hydraulic press is used on the mounted sensors to duplicate the actual condition during driving. This configuration is shown in Figure 13. 


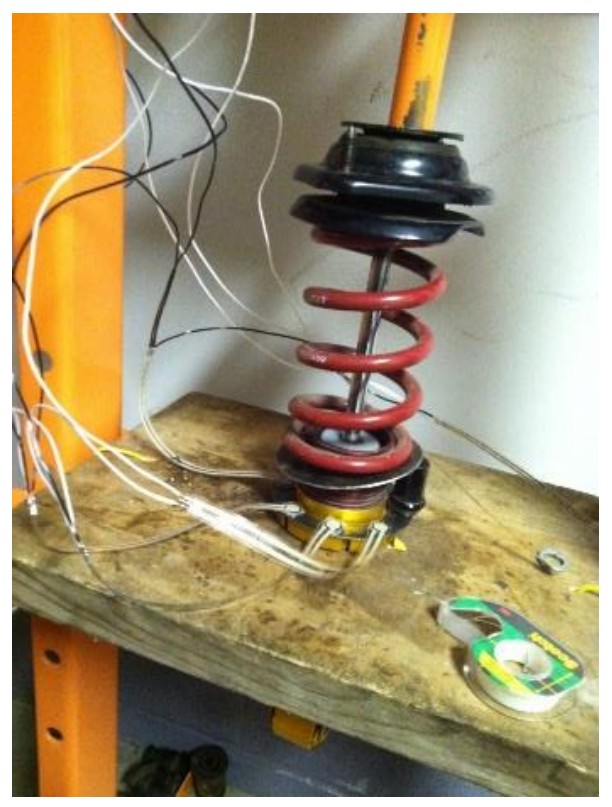

Figure-13 Coilover is fitted with sensors and mounting bracket about to be tested for functionality

After each corner was tested for functionality, the design was ready to be applied to the car. The sensors were mounted and wires were pulled from the passenger compartment to each wheel and its specific sensors with matching OpAmps electronic circuits. Most of the interior lining of the car was removed to perform wiring. Figure 14 shows the project fitted in the car.

The initial testing was done on a smooth straight road. The car was driven up to $80 \mathrm{mph}$ and the voltage changes were recorded. Later, the car was put on a car scale and the applied sufficient weight on the front or back to duplicate the measured voltage values from the road test. Table 1 shows these values.

Table-1 Voltage variation for different weight changes

\begin{tabular}{|r|r|}
\hline $\begin{array}{c}\text { Voltage Change } \\
(\mathbf{V})\end{array}$ & $\begin{array}{c}\text { Weight Change } \\
\text { (LBs) }\end{array}$ \\
\hline-0.03 & -250 \\
\hline-0.02 & -150 \\
\hline-0.01 & -60 \\
\hline 0.00 & 0 \\
\hline 0.01 & 60 \\
\hline 0.02 & 150 \\
\hline 0.03 & 250 \\
\hline 0.04 & 320 \\
\hline 0.05 & 420 \\
\hline 0.06 & 525 \\
\hline 0.07 & 600 \\
\hline 0.08 & 690 \\
\hline
\end{tabular}




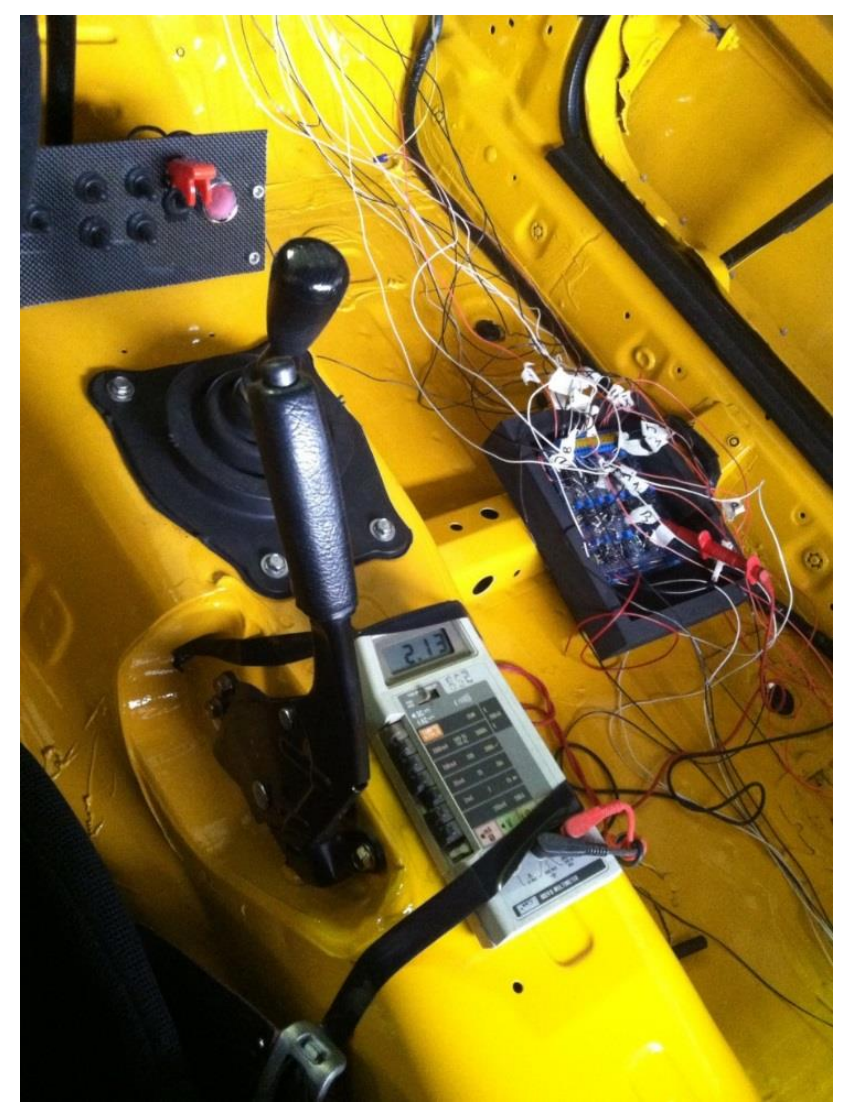

Figure-14 Installed sensors and completed wiring with a digital multi-meter to measure rear down forces

\section{RESULTS}

One of the tests for the car on the race track is called stock trim where the car is accelerated from a stop to $80 \mathrm{mph}$ resulted in a voltage change from 3.06 to 3.04 in the front and 2.34 to 2.35 in the rear. Comparing these measurements with values in Table-1 indicate that the car produced about $150 \mathrm{lbs}$. of lift in the front with $60 \mathrm{lbs}$. of downforce in the rear. With the wing installed at a horizontal angle of attack as well as the large front splitter, accelerating from $0-80 \mathrm{mph}$ the car made about $100 \mathrm{lbs}$. of lift in the front and about $250 \mathrm{lbs}$. of downforce in the rear. As a final test, the angle of attack is increased for the rear wing to give more downforce. This time the car was accelerated from 0 to $100 \mathrm{mph}$ and the car generated $690 \mathrm{lbs}$. of downforce in the rear and $150 \mathrm{lbs}$. of lift in the front.

\section{TRACK TESTING and CONCLUSION}

At Gingerman Raceway in Michigan, one complete day of test driving was performed. The car was driven for several laps on the race course as fast as it was possible both with and without aerodynamic aids. The car without the help of aerodynamic aid completed a course at 1:51.40 minutes. The same course was repeated with properly adjusted aerodynamic aids which took 1:49.33 minutes indicating an improvement of $1.31 \mathrm{mph}$ faster speed and it allowed the driver to maintain $70 \mathrm{mph}$ around the 2.13 mile track. The aerodynamic aid was a definite contributor in improving the lap times. 
The Aerodynamic aids have also helped the driver to win the $1^{\text {st }}$ and $2^{\text {nd }}$ places in 2014 racing season. This project demonstrated an experiential learning tool with true application of student and faculty cooperation in building something meaningful where engineering background and practice were fully utilized.

\section{REFERENCES}

1. B. J, Montomoli, F,A. D'Ammaro, "Uncertainty quantification and race car aerodynamics", Proceedings of the Institution of Mechanical Engineers, Part D: Journal of Automobile Engineering, Vol. 228, Pages: 403-411, ISSN: 0954-4070, 2014.

2. A. D'Hooge, L. Rebbeck, R. Palin, Q. Murphy, J. Gargoloff, and B. Duncan, "Application of Real-World Wind Conditions for Assessing Aerodynamic Drag for On-Road Range Prediction", Paper \#: 2015-01-155, SAE International 2015.

3. J. Dong, S. Erdogan, C. C. Lu C, and HS. Mahmassani, "State-Dependent Pricing for Real-Time Freeway Management: Static, Reactive, and Anticipatory", National Research Council (U.S.). Transportation Research Board Meeting $86^{\text {th }}$, Washington, D.C. 2,007.

4. J. Dong, H.S Mahmassani, R. Alfelor, "Incorporating Adverse Weather Impacts in Dynamic Traffic Simulation-assignment Models: Methodology and Application”, Submitted to Transportation Research Board Annual Meeting 2010.

5. M. Aiz, D. Valera, A. Alvarez \& A. Maduen, "A Wind Tunnel Study of Airflow through Horticultural Crops: Determination of the Drag Coefficient”, Biosystem Engineering, Vol.93, No.4, 2006, pp. 447-457.

6. R. H.Barnard and D. R. Philpott, "Aircraft Flight: a description of the physical principles of aircraft flight”, Essex, England: Longman Group Limited, 1995.

7. J. J. Bertin, and M. L. Smith, “Aerodynamics for Engineers", Third Edition, Upper Saddle River, NJ: Prentice-Hall, Inc., 1998.

8. Aerodynamics Upgradeshttp://www.academia.edu/2906183/aerodynamics_upgrades

9. D. Mitra, "Design estimation of Aerodynamic Angles of High Speed Cars", International Journal of Engineering Science and Technology, Vol.2, No.5, pp. 952-956, 2010. 